\title{
RELATANDO E REFLETINDO SOBRE AS EXPERIÊNCIAS DO PIBID BIOLOGIA (IF GOIANO - CÂMPUS URUTAÍ) NO PERÍODO DE 2011 A 2013
}

R. C. GONÇALVES, A. C. L. MARQUES, M. C. PÍCOLI, S. A. CARVALHO, E. S. GREGÓRIO, W. P. S. D'ORAZIO, K. F. G. SANTOS, T. P. SOUSA, V. G. MARCELO, R. V. O. CAETANO, A. D. SILVA JUNIOR, G. J. A. SILVA, J. F. OLIVEIRA, L. G. M. FARIA, A. P. SILVA, O. J. S. GONTIJO, P. S. RESENDE, M. A. S. B. ALVES e G. MALAFAIA* Instituto Federal Goiano - IF Goiano guilhermeifgoiano@gmail.com*

Artigo submetido em julho/2013 e aceito em dezembro/2014

DOI: $10.15628 /$ holos.2014.1480

\section{RESUMO}

O objetivo desse trabalho é relatar as experiências do PIBID Biologia (IF Goiano - Câmpus Urutaí), com destaque para as ações realizadas no Subprojeto de Ciências Biológicas; a visão dos supervisores bolsistas acerca da atuação e contribuição do programa na escola conveniada e na formação docente dos licenciandos; bem como a visão dos alunos bolsistas acerca da importância do subprojeto. Para a realização desse trabalho foi utilizada uma metodologia descritiva analítica, por meio da qual as atividades desenvolvidas foram relatadas de forma crítica e reflexiva. 0
Subprojeto de Ciências Biológicas (PIBID/IF Goiano Câmpus Urutaí) atualmente conta com 15 alunos bolsistas e 3 professores supervisores do Colégio Estadual Professor Ivan Ferreira (CEPIF), Pires do Rio, GO. De modo geral, pode-se dizer que as atividades desenvolvidas têm atingindo positivamente não apenas os alunos bolsistas, mas também a melhoria de aspectos diversos ligados ao ensino de Biologia na escola conveniada. O PIBID-Biologia tem possibilitado aos seus bolsistas uma aproximação de sua futura atuação profissional

PALAVRAS-CHAVE: Licenciatura, formação docente, PIBID.

\section{REPORTING AND REFLECTING ON THE EXPERIENCES OF PIBID-BIOLOGY (IF GOIANO - CÂMPUS URUTAÍ) FOR THE PERIOD FROM 2011 TO 2013}

\begin{abstract}
The objective of this study is to report the experiences of PIBID Biology (Instituto Federal Goiano - Câmpus Urutaí), highlighting the actions performed in Activity of Biological Sciences; vision of supervisors fellows on the performance and contribution of the program at the school and contracted teacher training of undergraduates, as well as the vision of scholarship students about the importance of the subproject. To conduct this study we used a descriptive analytical methodology, through which the activities have been reported in a critical and reflective. The subproject of
\end{abstract}

Biological Sciences (PIBID/IF Goiano - Câmpus Urutaí) currently has 15 scholarship students and 3 teachers supervisors Colégio Estadual Professor Ivan Ferreira (CEPIF), Pires do Rio, GO. In general, it can be said that the activities have positively affecting not only the scholarship students, but also the improvement of various aspects related to the teaching of biology in school contracted. The PIBID-biology has enabled its scholars an approximation of their future professional practice.

KEYWORDS: Degree, teacher training, PIBID 


\section{INTRODUÇÃO}

Atualmente, a educação escolar é sem dúvida um dos principais alicerces para a prática da cidadania e uma perspectiva de futuro promissor, na vida de qualquer ser humano (OLIVEIRA, 2009). Por isso, tem aumentado nas décadas mais recentes a discussão sobre a melhoria da qualidade do ensino básico oferecido no Brasil. Um dos maiores desafios para melhorar a qualidade da educação no contexto da educação básica é o estabelecimento de uma base sólida na formação inicial de professores. Conforme discutido por Braibante e Wollmann (2012), a educação básica de qualidade, implica na formação de educadores que estejam capacitados para atuarem no cotidiano da escola, o qual está em constante transformação em virtude dos avanços tecnológicos da sociedade. Desse modo, há a necessidade de se pensar e implantar políticas públicas/propostas para que os cursos de formação de professores cumpram sua finalidade.

Recentemente, o Programa Institucional de Bolsa de Iniciação à Docência (PIBID), criado pelo decreto $n$ ㅇ 7.219/2010 e financiado pela Coordenação de aperfeiçoamento de pessoal de nível superior (CAPES), vem se consolidando como uma das mais importantes iniciativas do país no que diz respeito à formação inicial de professores, surgindo como uma nova proposta de incentivo e valorização do magistério e possibilitando aos acadêmicos dos cursos de licenciatura a atuação em experiências metodológicas inovadoras ao longo de sua graduação (BRAIBANTE e WOLLMANN, 2012). Em linhas gerais o PIBID, tem como objetivo incentivar a formação docente, contribuir para a valorização do magistério, oportunizar experiências ligadas ao cotidiano escolar e contribuir para a articulação entre teoria e prática necessárias à formação dos docentes, elevando a qualidade das ações acadêmicas nos cursos de licenciaturas (CAPES, 2012).

Para Sarti (2009), a formação de um novo professor requer sua iniciação em valores, representações, saberes e fazeres que constituem a cultura pedagógica e estruturam a prática docente cotidiana. Essa iniciação corresponde a um longo e contínuo processo de socialização profissional que excede os limites das aprendizagens que as instâncias responsáveis pela formação inicial de professores são capazes de oferecer aos estudantes. Neste cenário, o PIBID apresenta aspectos positivos, uma vez que, possibilita aos graduandos dos cursos de licenciatura, vivenciar novas e profundas aprendizagens no cotidiano da escola, oferecendo experiências significativas de socialização profissional, a partir das quais se passa considerar as funções de um professor.

É importante ressaltar que o professor em início de carreira, ao chegar à realidade escolar, se depara com inseguranças, dilemas e dificuldades relacionadas à complexidade da profissão docente por ausência de maturidade profissional (SOUZA, 2009). Conforme discutido por Souza (2010), os profissionais que saem dos cursos de licenciaturas, muitas vezes, não estão preparados para lidarem com as situações rotineiras da escola, pois em algumas destas situações a teoria se distancia da prática e em outras, os profissionais não conseguem associar as teorias ali estudadas com a prática e a vivência do contexto escolar. Assim, muitos que concluem as licenciaturas e começam a exercer a docência se sentem decepcionados, culminando no abandono da profissão ou permanecendo sem a menor motivação, o que afeta ainda mais a qualidade do ensino (LOPES, 2010). 
O contato entre os estudantes que se dirigem ao magistério com um professor experiente em sua futura área de atuação parece constituir um recurso formativo privilegiado, pois pelo preparo psicopedagógico ligado à docência e maior segurança em suas ações, esses professores (docentes experientes) se configuram como guias e facilitadores no desenvolvimento profissional de professores novatos ou ainda em formação (SARTI, 2009). Pelo PIBID o licenciando tem a oportunidade de ter contato com o cotidiano da docência escolar e vivenciar experiências importantes no processo de sua formação.

Tendo em vista a necessidade de socialização de docentes principiantes com a cultura escolar, a oferta de programas de iniciação ao magistério tem sido apontado como uma estratégia adequada para a formação de professores, por contemplar um aprofundamento teórico em relação aos elementos que estruturam a prática docente cotidiana (CHARTIER, 2000). Nesse contexto, colocar estudantes de cursos de licenciaturas em vivências e dinâmicas do ambiente onde ocorre a educação básica é sem dúvida muito importante, pois cria conflitos, situações desafiadoras e, com isso, a busca por estratégias e/ou metodologias torna-se indispensável para o desenvolvimento de sua formação (BORGES, 2011).

Considerando a necessidade do conhecimento da realidade escolar, oportunizado por meio da vivência prática pelos licenciandos, o projeto institucional intitulado "Instrumentalização e co-formação de futuros professores nas diversas áreas do Ensino Fundamental, Médio e na Educação de Jovens e Adultos: Parceria entre o IFGoiano e as Escolas Básicas" foi aprovado no âmbito do Edital no 001/2011 da Coordenação de Aperfeiçoamento de Pessoal de Nível Superior (CAPES), com subprojetos na área de Ciências Biológicas, Química e Matemática.

O subprojeto de Ciências Biológicas do Câmpus Urutaí teve seu início no mês de julho do ano de 2011. A escola conveniada ao PIBID Biologia é o Colégio Estadual Professor Ivan Ferreira (CEPIF), localizado em Pires do Rio, GO. A referida instituição de ensino foi criada pela lei no 4.053, de 06 de julho de 1962. Atualmente, o CEPIF oferece à comunidade o ensino de nível médio, funciona no período diurno e noturno e atende cerca de 480 alunos. O PIBID Biologia, sob a responsabilidade de seu respectivo coordenador de área, atualmente conta com 15 alunos bolsistas e 3 professores supervisores. A concepção do referido projeto fundamenta-se em colocar os acadêmicos de Licenciatura em Ciências Biológicas do IF Goiano - Câmpus Urutaí em experiências iniciais ligadas à docência, visando à formação de futuro docente para a atuação na educação básica.

Nesta perspectiva, o objetivo desse trabalho é relatar as experiências do PIBID Biologia (IF Goiano - Câmpus Urutaí), com destaque para as ações realizadas; a visão dos supervisores bolsistas acerca da atuação e contribuição do programa na escola conveniada e na formação docente dos licenciandos; bem como a visão dos alunos bolsistas acerca da importância do subprojeto. Acreditamos que este trabalho possa contribuir para o desenvolvimento de ações futuras no âmbito do PIBID Biologia do Câmpus Urutaí (uma vez que instiga reflexões sobre as atividades já desenvolvidas), bem como pode servir de base para o desenvolvimento de novos subprojetos do PIBID aprovados recentemente pela CAPES. 


\section{MATERIAIS E MÉTODOS}

Para a realização desse trabalho utilizou-se uma metodologia descritiva analítico-reflexiva, por meio da qual os relatos das atividades desenvolvidas pelo PIBID Biologia do IF Goiano Câmpus Urutaí, mantidos em arquivo pelo grupo, foram analisados. Buscou-se relatar e refletir sobre as principais ações/atividades desenvolvidas entre o segundo semestre de 2011 e o primeiro semestre de 2013.

Para investigar a visão dos alunos bolsistas acerca do PIBID Biologia do IF Goiano Câmpus Urutaí, bem como a importância do subprojeto, aplicou-se um questionário investigativo por meio eletrônico aos 15 alunos bolsistas vinculados ao subprojeto, abrangendo a opinião dos discentes sobre o PIBID, o impacto e a contribuição do mesmo na sua formação docente e acadêmica. Além disso, buscou-se identificar as melhorias no curso de Ciências Biológicas/Licenciatura proporcionadas pelo PIBID, bem como se os objetivos do referido programa têm sido alcançados e qual a sua importância.

Para coleta dos dados junto aos supervisores bolsistas do PIBID Biologia, sobre atuação e contribuição do programa na escola conveniada e na formação docente dos licenciados, foi utilizado um questionário investigativo, composto por questões discursivas, aplicado por meio eletrônico aos três supervisores vinculados ao referido subprojeto.

\section{RESULTADOS E DISCUSSÕES}

O subprojeto PIBID Biologia está sendo desenvolvido tendo como base a compreensão que o ensino de Biologia, tem entre outras funções, a de contribuir para que os cidadãos sejam capazes de compreender e aprofundar explicações atualizadas de processos e de conceitos biológicos, visualizar a importância da ciência e da tecnologia na vida moderna e estimular o interesse pela realidade dos seres vivos (KRASILCHIK, 2004).

Desde sua implantação (julho de 2011) o PIBID Biologia desenvolveu diversas atividades na escola conveniada. Inicialmente o PIBID Biologia levantou vários dados e informações da escola conveniada, os quais permitiram a equipe traçar as primeiras estratégias de intervenção. As dificuldades ligadas ao ensino de Biologia, as opiniões e anseios dos alunos e professores, bem como pontos positivos e negativos ligados ao ensino da Biologia e perfil dos alunos e funcionários foram alguns dos aspectos levantados nessa etapa inicial. A partir dessa etapa, diversas atividades foram realizadas na escola conveniada, dentre elas: participação em reuniões de conselho de classe, participação no Trabalho Coletivo, Feira de Ciências, Feira do Sabor, participação no projeto "Bioética e Ciência", realização da "I Semana da Biologia", realização do projeto "PIBID - Biologia contra as Drogas", entre outros.

Visando a inserção dos pibidianos no ambiente escolar, os acadêmicos bolsistas participaram dos Trabalhos Coletivos e dos Conselhos de Classe como observadores (Figura 1). Por meio desta integração, os pibidianos tiveram a oportunidade de se aproximarem da realidade da escola conveniada ao programa. Os pibidianos participaram da Feira de Ciências e da Feira do Sabor do CEPIF como avaliadores, respectivamente, das produções científicas e receitas dos alunos (Figura 1). Esta ação possibilitou a integração dos bolsistas no contexto escolar no sentido de compreenderem a dinâmica de "projetos especiais" enquanto espaço sociocultural específico e como se da às relações de conhecimento nesse espaço. 
A necessidade de construir uma sociedade com cidadãos críticos, capazes de opinar sobre os dilemas éticos ligados a bioética levaram o PIBID a idealização de um projeto relacionado à Bioética (Figura 1). Na análise dos documentos que instrumentalizam as escolas, a Lei de Diretrizes e Bases da Educação (LDB) (BRASIL, 1996) e os Parâmetros Curriculares Nacionais (PCNs) (BRASIL, 1999), comungam a indicação da viabilidade de uma educação Bioética voltada ao ensino médio. Para Dumaresq et al. (2009), é interessante uma abordagem sobre os prováveis espaços que a Bioética pode ocupar no ensino médio, já que as transformações progressivas que estão ocorrendo em todos os campos do conhecimento humano desembocam, inevitavelmente, nas práticas educacionais, tornando-se cada vez mais essencial preparar os educandos, no sentido de que compreendam as implicações éticas da utilização do conhecimento biológico.

Com apoio logístico, os pibidianos auxiliaram na organização do projeto "Bioética e Ciência", o qual envolveu as turmas dos últimos anos do ensino médio. Em um primeiro momento, foi realizado um diagnóstico das percepções dos alunos da escola conveniada sobre questões pertinentes à Bioética por meio de um questionário investigativo. Notou-se, a partir deste diagnóstico, a necessidade de abordar assuntos relacionados à Bioética com os alunos, pois foi observado que a maioria dos discentes possuía pouco conhecimento acerca desta área do conhecimento. Neste projeto, de modo atrativo e inovador, foram realizadas mini-palestras, debates, mesa redonda e estudos de casos sobre os principais dilemas da Bioética na atualidade (aborto, eutanásia, células troncos e clonagem). As observações e a coparticipação, neste projeto, possibilitaram aos pibidianos a análise de metodologias de ensino-aprendizagem, interação professor-aluno e a dinâmica de "projetos especiais" na prática pedagógica.

Atualmente, há uma preocupação crescente com o desenvolvimento de procedimentos didáticos referentes aos processos de ensino que possibilite aos alunos a promoção da compreensão e assimilação dos conteúdos ministrados. Considerando, de acordo com Malafaia et al. (2010), a necessidade de atividades inovadoras no contexto do cotidiano do aluno, as quais fogem das aulas convencionais, centrada na figura do professor e na postura passiva dos alunos, que, infelizmente, ainda persistem na atualidade, foi realizada a "I Semana da Biologia" no CEPIF (Figura 2).

Este projeto abordou, por meio de minicursos/oficinas, vídeos, experimentação e atividades lúdicas temas cobrados nos exames de vestibulares, de um modo mais prático e dinâmico. A "I Semana da Biologia" foi realizada em contra turno para alunos do 3o ano do ensino médio do período da manhã com a participação de 20 alunos/dia. Na ocasião, os pibidianos foram divididos em duplas que ficaram responsáveis pelo desenvolvimento de uma atividade ligada a uma área específica da Biologia, sendo elas: Botânica, Zoologia, Genética, Citologia e Fisiologia humana. Os temas foram abordados de forma expositivo-dialógica, com demonstração de vídeos referentes às áreas e realização de atividades práticas, expondo materiais e métodos e realizando pequenos experimentos. Com essa experiência aproximou-se os pibidianos ao contexto da docência e aproximou os alunos participantes a temas da Biologia ainda distantes de sua realidade. 

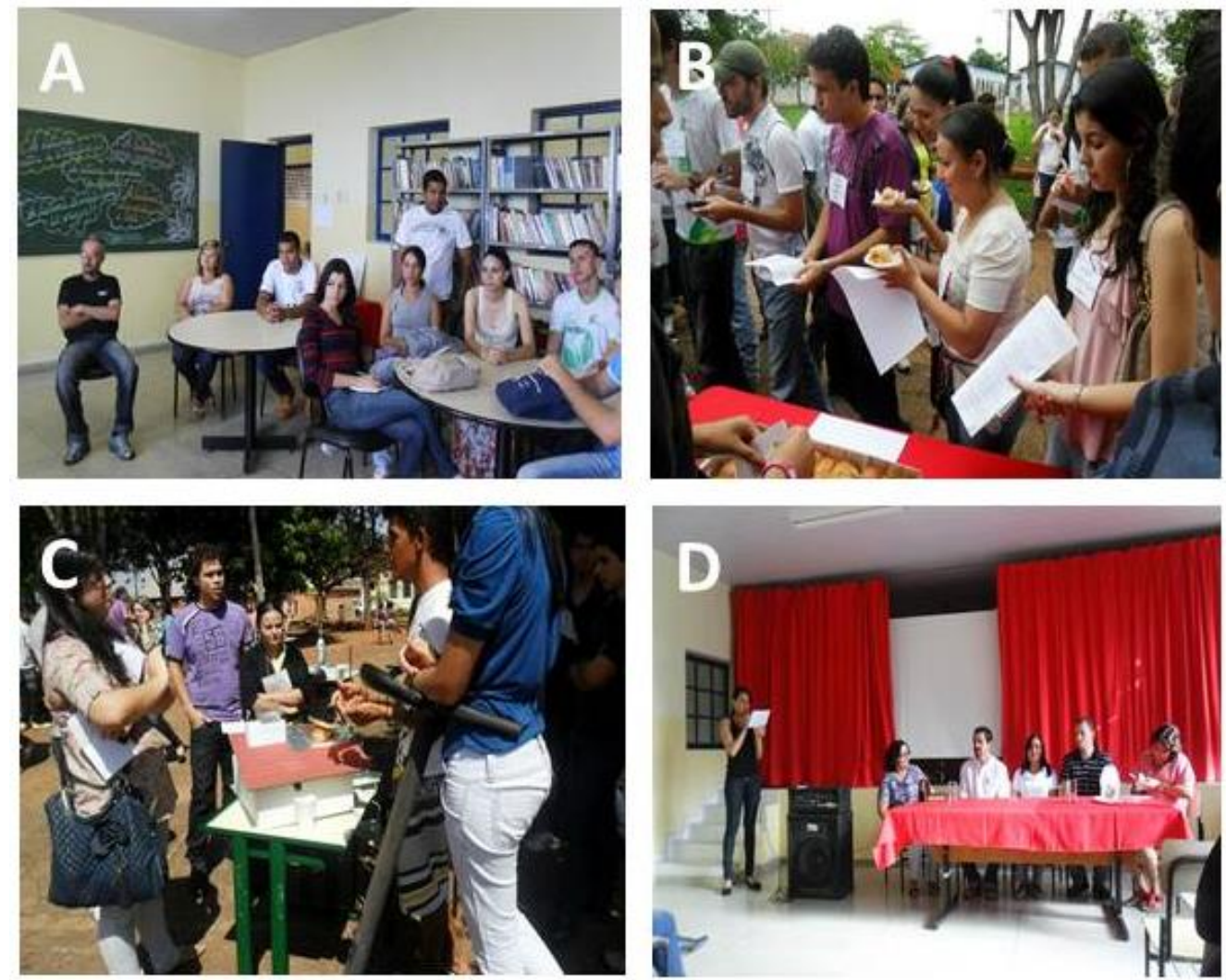

Figura 1. Ações desenvolvidas pelo PIBID Biologia (IF Goiano - Câmpus Urutaí). A: Participação dos pibidianos no Trabalho Coletivo. B: Pibidianos avaliando as produções científicas dos alunos na Feira de Ciências. C: Participação dos pibidianos na Feira do Sabor. D: Mesa redonda no Projeto "Bioética e Ciência"

Considerando que, uma das etapas mais importante do desenvolvimento humano, que suscita preocupações em relação ao uso de substâncias psicoativas como álcool e drogas ilícitas é a adolescência (BUCHER, 1992; ALMEIDA FILHO et al., 2007; MALTA et al., 2011) e que o consumo destas substâncias em idade escolar está associado com o desempenho escolar dos jovens (TAVARES et al., 2001 e STRAUCH et al., 2009), outro projeto desenvolvido no âmbito do subprojeto de Ciências Biológicas foi o "PIBID Biologia Contra as Drogas" (Figura 2).

O objetivo do referido projeto foi conscientizar e alertar os alunos da escola conveniada sobre as causas e riscos de algumas drogas, além de fazer com que os acadêmicos bolsistas estudassem mais a fundo o assunto e aplicassem o conhecimento adquirido em âmbito escolar. Para fundamentar esse projeto, os acadêmicos bolsistas aplicaram em sala de aula um questionário exploratório do qual foram levantados os dados sobre os possíveis tipos de drogas que poderiam ser usados pelos alunos do CEPIF e as variáveis relacionadas com seu uso. A partir daí dividiram-se os temas e cada um dos bolsistas se responsabilizou pelo desenvolvimento de palestras relacionadas a cada tipo de drogas (Álcool, Cigarro, Cocaína, Crack, Maconha e uso de Drogas na Gravidez).

As palestras foram ministradas com todo ensino médio do período matutino contando com 11 turmas atingindo aproximadamente 300 alunos que foram divididos em cinco turmas de aproximadamente 60 alunos por dia. Durante e após as palestras foram alcançados os objetivos do projeto, visto que além de despertar a atenção e instigar a reflexão em massa dos alunos do 
CEPIF, somou-se maior experiência para os bolsistas envolvidos em relação à abordagem desse assunto em âmbito escolar.

Considerando o papel relevante do teatro no contexto educacional outra atividade promovida pelo PIBID Biologia, foi a realização de um peça na escola conveniada (Figura 2). 0 teatro pode ser uma interessante estratégia a ser utilizada no contexto educacional para despertar valores, ideias e aprimorar conceitos e opiniões. De acordo com Oliveira (2004), o teatro desenvolve nos alunos, o sentimento, a sensibilidade, a intuição e o pensamento, sendo um recurso que facilita o processo de ensino e aprendizagem. Miranda et al (2009) afirmam que o teatro devidamente utilizado, auxilia no desenvolvimento do aluno como um todo, despertando o gosto pela leitura, promovendo a socialização, melhora a aprendizagem dos conteúdos propostos pela escola, faz repensar e querer modificar a realidade instaurada. Ademais, possui caráter lúdico e constitui-se como forma de lazer.

O teatro foi desenvolvido por bolsistas do PIBID Biologia, acadêmicos do grupo de teatro "MutAÇÃO" e o grupo PET-Bio, todos do IF Goiano - Câmpus Urutaí. Tal peça, intitulada "Os sonhos da nação brasileira" teve como foco a responsabilidade de votar conscientemente, o que consequentemente poderia refletir na melhoria da educação e da saúde pública do país, em um maior investimento em tecnologias, na preservação da fauna e flora brasileira, entre outros. A peça tratou ainda de enfatizar a importância da constituição brasileira.

O PIBID Biologia promoveu também, juntamente com os discentes da escola conveniada, oficinas para a construção de materiais didático-pedagógicos (Figura 2). Tais oficinas tiveram como objetivo oportunizar aos alunos do CEPIF o contato direto com a prática de assuntos abordados na Biologia Celular (Mitose e Meiose), Botânica e Zoologia dos Invertebrados, de um modo mais dinâmico, além de criar situações de envolvimento docente aos pibidianos. A construção dos modelos e/ou materiais didático-pedagógicos foram referentes às áreas da Biologia mencionadas, envolvendo turmas do 1 , 20 e 30 ano do ensino médio, tendo ocorrido uma atividade teórica sobre os temas anteriormente. Priorizou-se a utilização de materiais de baixo custo e de fácil acesso.

Os materiais utilizados para a construção dos modelos didáticos referentes à Mitose e Meiose foram: bolas de isopor, parafina e massa de modelar representando, respectivamente, a membrana plasmática, citoplasma e organelas. Para a confecção do material didático da botânica utilizou-se folhas vegetais desidratadas e papel A4 para ser construído um catálogo de identificação. Em relação ao material didático-pedagógico da Zoologia dos Invertebrados, propôsse a confecção de um Artropodário, que utilizou insetos devidamente tratados com formol, uma caixa feita para tal atividade e isopor para fixar os insetos dentro da caixa.

Como resultados dessa atividade, destacam-se o envolvimento dos discentes da escola conveniada nas atividades desenvolvidas, a maior empolgação e motivação dos mesmos em relação à disciplina Biologia, bem como o maior envolvimento dos bolsistas do PIBID-Biologia em situações de práticas docente que envolvem a construção de modelos e/o materiais didáticopedagógicos atrelada ao ensino e aprendizagem de conteúdos biológicos. Os materiais construídos estão servindo de acervo pedagógico ao Laboratório de Ciências do CEPIF para o desenvolvimento de aulas da escola conveniada. 

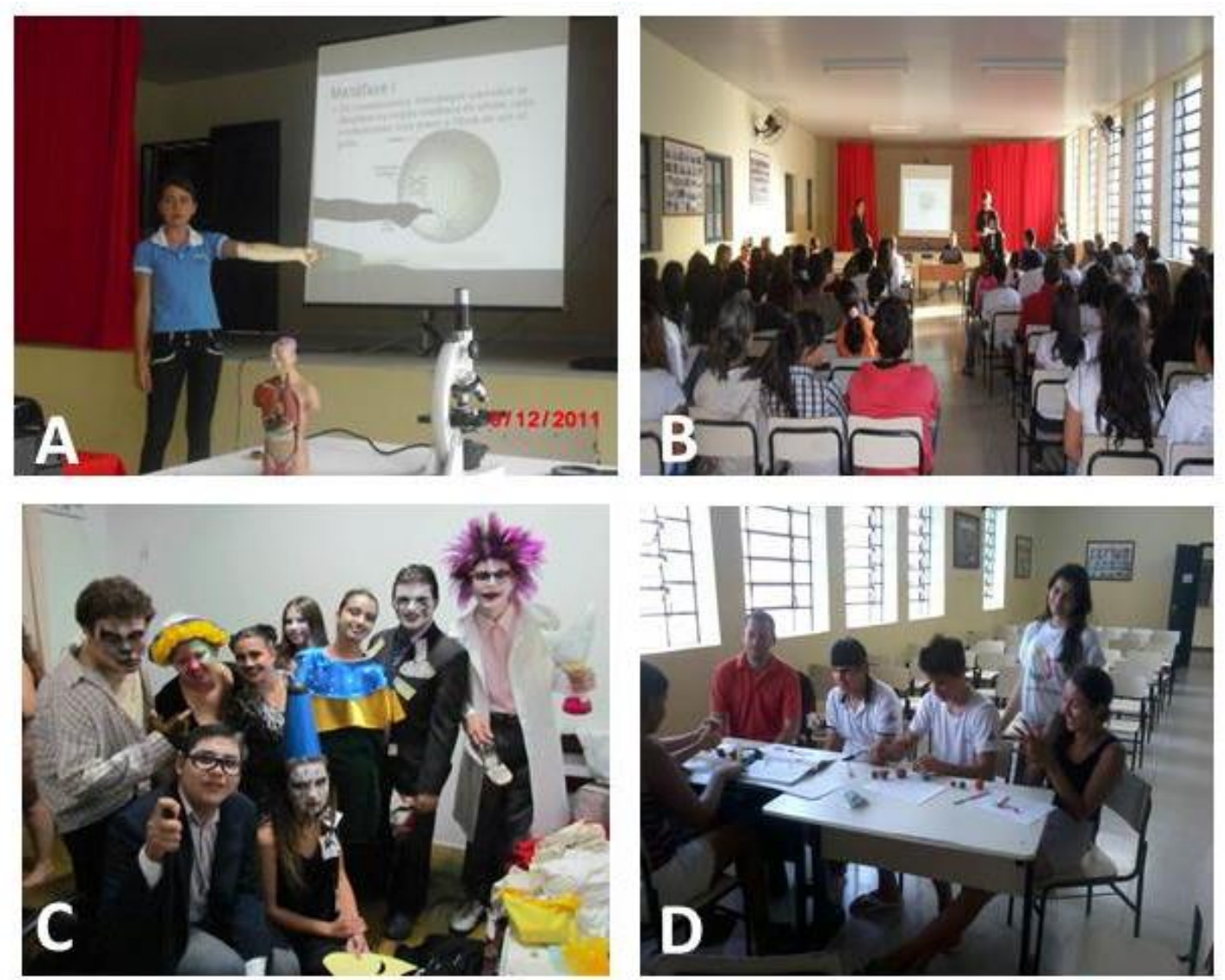

Figura 2. Ações desenvolvidas pelo PIBID Biologia (IF Goiano - Câmpus Urutaí). A: Pibidiano explicando o processo de divisão celular na "I Semana de Biologia”. B: Projeto "PIBID - Contra as drogas". C: Peça de teatro "Os sonhos da nação brasileira" desenvolvido por acadêmicos do PIBID Biologia, do grupo de teatro “MutAÇÃO" e do grupo PET-Bio. D: Construção de materiais didáticos (célula animal) com os alunos do CEPIF durante a realização de uma oficina.

Considerando que as doenças sexualmente transmissíveis (DST's) constituem um sério problema de saúde pública, na atualidade e que a incidência e prevalência das mesmas têm aumento significativo entre adolescentes, foram realizadas diversas palestras sobre $o$ assunto (Figura 3). Esta ação teve o objetivo de proporcionar a formação e/ou o aprimoramento de conceitos, bem como informar e instruir alunos da escola conveniada sobre as DST's. A atividade foi desenvolvida propositalmente em período que antecedeu o carnaval de 2013 (5 a 8 de fevereiro de 2013), considerando que esse período de festividades é crítico para relações casuais e inconsequentes, culminando, normalmente, em um aumento dos casos de DST's.

A metodologia usada nessa ação envolveu o desenvolvimento de palestras ministradas pelos bolsistas, acompanhadas de um especialista no assunto. Participaram dessa atividade 135 alunos, de todas as séries do ensino médio (período noturno). A formação ou aprimoramento dos conceitos dos alunos sobre DST's foi avaliada por meio de um questionário o qual foi respondido pelos alunos antes e após o desenvolvimento da atividade. $O$ instrumento buscou avaliar o conhecimento dos discentes sobre a importância dos preservativos, sobre os métodos de prevenção, sobre as formas de transmissão das principais DST's, dentre outros aspectos. 
Os resultados obtidos indicam que a atividade realizada permitiu a formação de novos conceitos ligados às DST's, assim como o aprimoramento de alguns conceitos pré-existentes. Foi possível observar que as palestras sensibilizaram os alunos para a importância da utilização dos métodos de prevenção, estimularam os jovens a realizarem perguntas e a sanarem suas dúvidas. A grande maioria dos jovens afirmou que aprendeu sobre as formas de contágio, como se prevenir e sobre o que se deve e o que não se deve fazer em relação às DST's. Portanto, concluiuse que a atividade não apenas informou e instruiu os jovens estudantes sobre as DST's, assim como contribuiu para a formação e/ou aprimoramento de conceitos técnicos ligados à temática abordada.

Visando à integração dos subprojetos atuantes no Colégio Estadual Professor Ivan Ferreira (Ciências Biológicas e Química, ambos do IF Goiano - Câmpus Urutaí; Letras, História e Geografia, da Universidade Estadual de Goiás, Unidade de Pires do Rio), o PIBID Biologia organizou e promoveu o "I Encontro de Socialização do PIBID" (Figura 3). Esse encontro foi um momento muito importante de reflexão sobre a atuação do PIBID e as ações desenvolvidas por cada subprojeto na escola conveniada.

Outra atividade desenvolvida pelo PIBID Biologia trata-se do workshop com o tema alimentação saudável, considerando que a alimentação e nutrição adequadas são essenciais para o crescimento e desenvolvimento com qualidade de vida, bem como para a prevenção de doenças e para manter o desempenho de escolares em sua capacidade de aprender (Figura 3). 0 workshop envolveu adolescentes do 1 을 ano do ensino médio e abordou as propriedades dos alimentos, quais são mais essenciais e que podem ser consumidos em maior e menor quantidades, quais doenças estão relacionadas à carência nutricional e a obesidade, bem como os malefícios e benefícios associados aos hábitos alimentares. Posteriormente, aplicou-se um questionário investigativo contendo questões objetivas e discursivas de caráter individual. Por meio dessa sondagem, notou-se que apesar dos adolescentes terem a informação sobre o que seriam hábitos saudáveis, a preferência ainda é alimentos denominados fast food.

A intervenção mais recente e ainda em andamento do PIBID Biologia refere-se à revitalização do Laboratório de Ciências do CEPIF (organização do espaço, levantamento de materiais disponíveis para experimentação, construção de materiais didático-pedagógicos, etc.). Acredita-se que com essa iniciativa, o PIBID oferecerá ao educador supervisor do programa e demais educadores da escola conveniada, alternativas para melhorar o ensino e aprendizagem por meio de aulas mais dinâmicas e atrativas. É interessante ressaltar, que a importância das atividades práticas e/ou laboratoriais (experimentação) é inquestionável, uma vez que tem demonstrado contribuir com o aprendizado dos alunos e com a motivação pelas aulas de Biologia (MOREIRA et al., 2003). Sobre este aspecto, vários estudos já demonstraram a importância do desenvolvimento de aulas práticas no ensino de Biologia (CAMPOS \& DINIZ, 2001; MOREIRA et al., 2003; POSSOBOM et al. 2003; KELLER et al., 2011).

Em relação à participação em eventos acadêmicos e à publicação de trabalhos científicos, os pibidianos já participaram da II Jornada de Iniciação Científica (IF Goiano - Câmpus Urutaí), II Encontro Nacional de Licenciatura e I Seminário Nacional do PIBID, (UFG/Goiânia), II Fórum Mundial de Educação Profissional e Tecnológica (UFSC/ Florianópolis), XIII Simpósio de Biologia (UEG/Quirinópolis), III Ciclo de palestras e I Mostra Científica de Ciências Biológicas (IF Goiano Campus Urutaí), I Congresso Estadual de Iniciação Científica do Instituto Federal Goiano (IFGoiano/ Urutaí), III Encontro Nacional das Licenciaturas e II Seminário Nacional do PIBID 
(UFMA/Maranhão) e I Semana dos Cursos Superiores e I Encontro do PIBID (IFG/Luziânia). Mais de 30 resumos já foram publicados, e três manuscritos já foram submetidos a diferentes periódicos científicos.

O presente trabalho também procurou conhecer a visão dos alunos bolsistas acerca do PIBID Biologia, com destaque para a importância do subprojeto, o impacto e a contribuição do mesmo na sua formação docente e acadêmica, quais as melhorias o PIBID proporcionou no curso de Licenciatura em Ciências Biológicas, bem como se os objetivos do programa têm sido alcançados. Ao serem questionados sobre a opinião acerca do PIBID, os alunos bolsistas o descreveram como um programa diferenciado dos demais presentes no IF Goiano, pois se destaca por propiciar aos alunos da graduação uma aproximação da futura profissão, oferecendo experiência docente, vivência no âmbito escolar e melhoria no ensino de Biologia à escola pública conveniada ao subprojeto.

No que se refere às contribuições do PIBID para a formação acadêmica, os licenciandos relataram a oportunidade de conhecer e enfrentar as dificuldades e desafios do papel do professor, a inserção no meio científico por meio da elaboração de resumos e artigos científicos e a melhor desenvoltura diante do público. O PIBID, segundo os bolsistas, tem proporcionado maior estímulo à integralização do curso de Licenciatura em Ciências Biológicas, diminuindo a evasão no curso. Em relação aos objetivos, os alunos consideraram que todos têm sido alcançados, uma vez que as ações propostas são sempre planejadas com vínculo direto aos objetivos do programa.
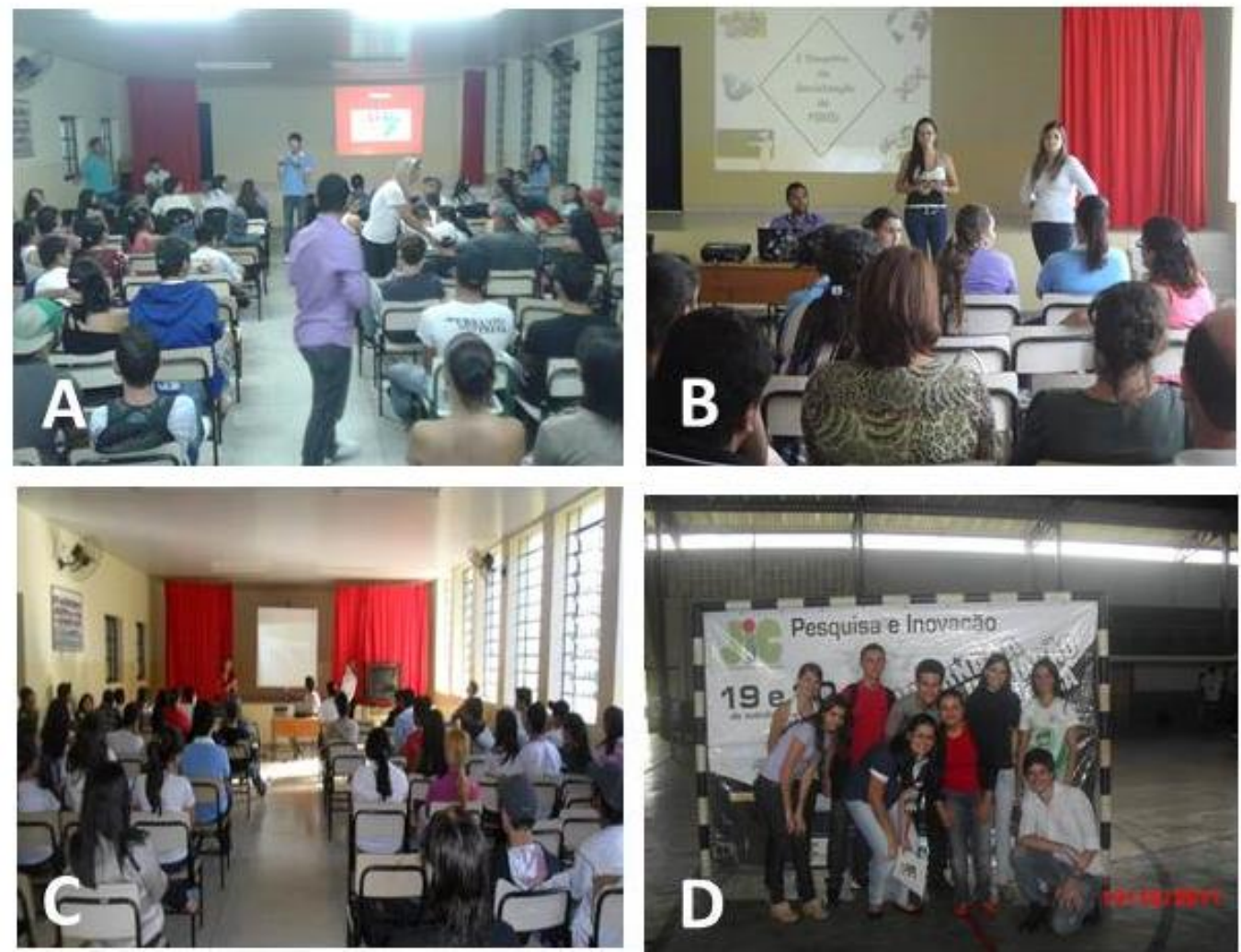

Figura 3. Ações desenvolvidas pelo PIBID Biologia (IF Goiano - Câmpus Urutaí). A: Palestras sobre DST’s. B: “I Encontro de Socialização do PIBID”. C: Workshop com o tema alimentação saudável. D: Pibidianos na Jornada de Iniciação Científica do IF Goiano - Urutaí. 
Outro ponto importante relacionado ao PIBID refere-se à visão dos supervisores bolsistas do programa, sobre atuação e contribuição do PIBID Biologia na escola conveniada e na formação docente dos licenciandos. Todos os supervisores reconheceram que o subprojeto tem sido importante para a formação docente dos bolsistas, onde os alunos atuam realizando atividades diversas ligadas à docência que ajudam na formação e interação com a realidade escolar, possibilitando o desenvolvimento de competências possíveis de serem adquiridas apenas no exercício da profissão, além de incentivar na escolha da carreira docente e melhoria da oratória.

Quanto à contribuição do PIBID Biologia para a melhoria do ensino de Biologia no CEPIF, os supervisores relataram que o mesmo tem despertado maior interesse pela disciplina (Biologia) e com o desenvolvimento dos projetos, o índice de notas baixas diminuiu em relação às turmas de anos anteriores, fato que mostra que o PIBID contribuiu para a melhoria da aprendizagem dos discentes do CEPIF. Em relação aos objetivos almejados inicialmente pelo subprojeto, os supervisores acreditam que os mesmos vêm sendo alcançados, pois as atividades desenvolvidas têm abordado diferentes áreas diversificadas das Ciências Biológicas e da Educação, o que contribui para um ensino-aprendizado dinâmico e eficaz.

Como ponto negativo, os supervisores destacaram a falta de interação efetiva entre os subprojetos do PIBID atuantes na escola e sugeriram que estes realizem encontros para socialização e sistematização para ações conjuntas, a exemplo do encontro organizado pelo PIBID Biologia. Destaca-se que no "I Encontro de Socialização do PIBID" foi entregue à comunidade escolar, a 1a edição do Jornal Informativo do PIBID Biologia, jornal esse editado pelos próprios pibidianos, o qual teve como intuito proporcionar uma maior divulgação sobre o programa e sobre as atividades desenvolvidas pelo subprojeto de Ciências Biológicas.

É importante chamar a atenção para o fato de que toda ação do PIBID Biologia parte de uma reflexão sobre a realidade escolar. Para tanto, antes de cada intervenção ou atividade a ser realizada, ocorre uma pré-análise do conhecimento e dos anseios dos alunos da escola conveniada, por meio da aplicação de questionário investigativo. Além disso, com o intuito de facilitar a compreensão da linguagem científica, estimular a leitura e interpretação de textos, bem como de analisar a aplicabilidade de propostas de intervenção no CEPIF e de novas práticas didáticas, há sempre estudo e discussões/debates em algum referencial teórico na área de Educação, Ensino de Ciências e/ou de Biologia. Também ocorrem encontros (reuniões) entre alunos bolsistas, supervisores e coordenador de área para socialização e sistematização das ações do PIBID Biologia no decorrer das atividades.

\section{CONCLUSÃO}

Conclui-se com esse trabalho que há compatibilidade entre os objetivos descritos no subprojeto PIBID Biologia e as reais ações desenvolvidas na escola conveniada ao programa. As repercussões das atividades desenvolvidas têm atingindo positivamente não apenas os alunos bolsistas (no sentido de contribuir significativamente para a formação dos mesmos), mas também com a melhoria de aspectos diversos ligados ao ensino de Biologia na escola conveniada. Além disso, pode-se dizer que o PIBID Biologia tem possibilitado integrar e aproximar os alunos do curso de Licenciatura em Ciências Biológicas ao campo de ação do profissional docente, bem como estimulado o desenvolvimento de novas metodologias de ensino que podem ser úteis na sua atuação futura, enquanto professores da Educação Básica. 


\section{REFERÊNCIAS BIBLIOGRÁFICAS}

1. ALMEIDA FILHO, J. A.; FERREIRA, M. A.; GOMES, M. L. B.; SILVA, R. C.; SANTOS, T. C. F. O adolescente e as drogas: consequências para a saúde. Revista de Enfermagem, 11(4):605-10, 2007.

2. BORGES, A. A. T. ; DORZIO, W. P. S. ; CARVALHO, S. A. ; PICOLI, M. C.; MARQUES, A. C. L. ; GREGORIO, E. S. ; LIMA, T. H. ; ALVES, M. A. S. B. ; SOUSA, T. P. ; RESENDE, P. S. ; GONCALVES, R. C. ; MALAFAIA, G. Concepções e opiniões de discentes do colégio estadual professor Ivan Ferreira (Pires do Rio, Go) sobre a biologia e o seu ensino. In: I Congresso Estadual de Iniciação Científica e I Semana de Formação Docente em Educação para a Ciência, 2012, Urutaí. Anais do I Congresso Estadual de Iniciação Científica e I Semana de Formação Docente em Educação para a Ciência, 2012.

3. BRAIBANTE, M. E. F.; WOLLMANN, E. M. A Influência do PIBID na Formação dos Acadêmicos de Química Licenciatura da UFSM. Química nova na escola, 34(4):167-172, 2012.

4. BRASIL. Lei n.9.394/96. Diretrizes e bases da educação nacional, aprovada na Câmara Federal em 17/12/96 e sancionada pelo Presidente da República em 20/12/96. Brasília: Ministério da Educação e Cultura, 1996.

5. BRASIL. Parâmetros Curriculares Nacionais: ensino médio. Brasília: Ministério da Educação e Cultura, 1999.

6. BUCHER, R. Drogas e drogadição no Brasil. Porto Alegre: Artes Médicas; 1992.

7. CAMPOS, L. M. L.; DINIZ, R. E. S. A prática como fonte de aprendizagem e o saber da experiência: o que dizem professores de Ciências e de Biologia. Investigações em Ensino de Ciências, 6(1): 79-96, 2001.

8. CHARTIER, A. M. Fazeres ordinários da classe: uma aposta para a pesquisa e para a formação. Educação e Pesquisa, 26(2):157-168, 2000.

9. COORDENAÇÃO DE APERFEIÇOAMENTO DE PESSOAL DE NÍVEL SUPERIOR (CAPES). Programa Institucional de Bolsa de Iniciação à Docência (PIBID). Disponível em: http://www.capes.gov.br/educacao-basica/capespibid. Acesso em: 08 de agosto de 2012.

10. DALBEN, A. I. L.F. (2004) Conselhos de classe e avaliação do projeto-político -pedagógico da escola. Revista Presença Pedagógica (nov/dez. 2004.) Minas Gerais.

11. DUMARESQ, M. I. A.; PRIEL, M. R.; ROSITO, M. M. B. A Educação Bioética. Contraponto, 9(2):66-76, 2009.

12. KELLER, L.; BARBOSA, S.; BAIOTTO, C. R.; SILVA, V. M. A importância da experimentação no ensino de Biologia. In: XVI Seminário Interinstitucional de Ensino, Pesquisa e Extensão, p. 1-3, 2011.

13. KRASILCHIK, M. Prática de ensino de Biologia. 4 Ed. São Paulo: Editora da USP, 2004.

14. LOPES, R. P. Da licenciatura à sala de aula: o processo de aprender a ensinar em tempos e espaços variados. Educar, Curitiba, n. 36, 2010.

15. MALAFAIA, G.; BÁRBARA, V. F.; RODRIGUES, A. S. L. Análise das concepções e opiniões de discentes sobre o ensino de Biologia. Revista Eletrônica de Educação, 4(2):165-182, 2010.

16. MALTA, D. C.; MASCAREnhAS, M. D. M.; PORTO, D. L.; DUARTE, E. A.; SARDINHA, L. M.; 
BARRETO, S. M.; MORAIS NETO, O. L. Prevalência do consumo de álcool e drogas entre adolescentes: análise dos dados da Pesquisa Nacional de Saúde Escolar. Revista Brasileira de Epidemiologia, 14(1):136-46, 2011.

17. MIRANDA, J. L.; ELIAS, R. M.; FARIA, R. ; SILVA, V. L.; FELíCIO, W. A. S. Teatro e a escola: funções, importâncias e práticas. Revista CEPPG, no 20, 172-181, 2009.

18. MOREIRA, M. L.; DINIZ, R. E. S. O laboratório de Biologia no Ensino médio: infraestrutura e outros aspectos relevantes. In: Universidade Estadual Paulista - Pró-Reitoria de Graduação. (org.), Núcleos de Ensino. São Paulo: Editora da UNESP, 2003.

19. OLIVEIRA, M. V. C. Teatro na escola: Uma ferramenta criativa e um desafio ao educador. Monografia (especialização), Universidade Candido Mendes, Rio de Janeiro, 2004.

20. POSSOBOM, C. C. F.; OKADA, F. K.; DINIZ, R. E. S. Atividades práticas de laboratório no ensino de Biologia e de Ciências: relato de uma experiência, 2003. Disponível em: $<$ www.unesp.br/prograd/PDFNE2002/atividadespraticas. Acesso em 12 de fevereiro de 2012.

21. SARTI, F. M. Parceria intergeracional e formação docente. Educação em Revista, 25(02):133152, 2009.

22. SOUZA, C. F.; FERREIRA, D. A.; NETTO, G. F.; ROSA, I. C. P.; FERREIRA, R. G.; MELO, R. E. B. A Relação entre Universidade, Escola e Comunidade através das ações do PIBID. In: Anais do II Simpósio de Matemática e Matemática Industrial, Vol. 1, ISSN 2175-7828, 2010.

23. SOUZA, D. B. Os dilemas do professor iniciante: reflexões sobre os cursos de formação inicial. Revista multidisciplinar da UNIESP, no 08, 2009.

24. STRAUCH, E. S.; PINHEIRO, R. T.; SILVA, R. A.; HORTA, B. L. Uso do álcool por adolescentes: estudo de base populacional. Revista de Saúde Pública, 43(4):647, 2009.

25. TAVARES, B. F.; BÉRIA J. U.; LIMA, M. S. Prevalência do uso de drogas e desempenho escolar entre adolescentes. Revista Saúde Pública, Rev Saúde Pública, 35(2):150-158, 2001.

26. TEIXEIRA, P. M. M.; NETO, J. M. Investigando a pesquisa educacional. Um estudo enfocando dissertações e teses sobre o ensino de Biologia no Brasil. Investigações em Ensino de Ciências, 11(2): 261-282, 2006. 